\title{
Pharmacological Dissection of Intrinsic Optical Signal Reveals a Functional Coupling between Synaptic Activity and Astrocytic Volume Transient
}

\author{
Junsung Woo ${ }^{1 \dagger}$, Young-Eun Han ${ }^{1,2,3 \dagger}$, Wuhyun $\operatorname{Koh}^{1,2,3}$, Joungha Won ${ }^{1,3,4}$, \\ Min Gu Park ${ }^{1,3,5}$, Heeyoung $\mathrm{An}^{1,3,5}$ and C. Justin Lee $\mathrm{Le}^{1,2,3 *}$ \\ ${ }^{1}$ Center for Glia-Neuron Interaction, Korea Institute of Science and Technology (KIST), Seoul 02792, ${ }^{2}$ Department of \\ Neuroscience, Division of Bio-medical Science \& Technology, KIST School, Korea University of Science and Technology, \\ Seoul 02792, ${ }^{3}$ Center for Cognition and Sociality, Institute for Basic Science (IBS), Daejeon 34126, ${ }^{4}$ Department of Biological \\ Sciences, Korea Advanced Institutes of Science and Technology (KAIST), Daejeon $34141,{ }^{5} \mathrm{KU}-\mathrm{KIST}$, Graduate School of \\ Converging Science and Technology, Korea University, Seoul 02841, Korea
}

The neuronal activity-dependent change in the manner in which light is absorbed or scattered in brain tissue is called the intrinsic optical signal (IOS), and provides label-free, minimally invasive, and high spatial $(\sim 100 \mu \mathrm{m})$ resolution imaging for visualizing neuronal activity patterns. IOS imaging in isolated brain slices measured at an infrared wavelength $(>700 \mathrm{~nm})$ has recently been attributed to the changes in light scattering and transmittance due to aquaporin-4 (AQP4)-dependent astrocytic swelling. The complexity of functional interactions between neurons and astrocytes, however, has prevented the elucidation of the series of molecular mechanisms leading to the generation of IOS. Here, we pharmacologically dissected the IOS in the acutely prepared brain slices of the stratum radiatum of the hippocampus, induced by $1 \mathrm{~s} / 20 \mathrm{~Hz}$ electrical stimulation of Schaffer-collateral pathway with simultaneous measurement of the activity of the neuronal population by field potential recordings. We found that $55 \%$ of IOSs peak upon stimulation and originate from postsynaptic AMPA and NMDA receptors. The remaining originated from presynaptic action potentials and vesicle fusion. Mechanistically, the elevated extracellular glutamate and $\mathrm{K}^{+}$during synaptic transmission were taken up by astrocytes via a glutamate transporter and quinine-sensitive K2P channel, followed by an influx of water via AQP-4. We also found that the decay of IOS is mediated by the DCPIB- and NPPB-sensitive anion channels in astrocytes. Altogether, our results demonstrate that the functional coupling between synaptic activity and astrocytic transient volume change during excitatory synaptic transmission is the major source of IOS.

Key words: Intrinsic optical signal, Astrocyte volume, K2P channel, NPPB-sensitive anion channel, Activity-dependent astrocyte volume change

Received January 27, 2019, Revised February 12,2019,

Accepted February 14, 2019

\footnotetext{
* To whom correspondence should be addressed.

TEL: 82-42-878-9150, FAX: 82-42-878-9151

e-mail: cjl@ibs.re.kr

These authors are contributed equally to this work.
}

\section{INTRODUCTION}

Intrinsic optical signal (IOS) imaging is a label-free and minimally invasive imaging technique that represents changes in light absorption or scattering as the spatiotemporal neural activity. IOS 
imaging is readily observed at the cellular level in a single neuron (in vitro) or in the human brain (in vivo) [1-5]. Many previous studies have reported that IOS originated from activity-dependent changes in several parameters such as blood volume, the ratio of oxy/deoxygenated hemoglobin, and light scattering with cell swelling, which can be separately measured by varying the wavelength of light [6-8]. Measuring IOS signal at the near-infrared region $(>700 \mathrm{~nm})$ has several advantages, such as deeper penetration into brain slices or tissue and a minimal contribution of the absorption from either hemoglobin usually measured at around $630 \mathrm{~nm}$ [9] or cytochrome, such as porphyrins, measured at $440 \mathrm{~nm}$ [10]. The IOS signal under infrared wavelength has been shown to be dominated by light scattering with both activity-dependent astrocyteswelling by the ionic movement associated with water and the reduction of the extracellular volume $[1,7,8,11]$. However, the detailed molecular mechanisms underlying IOS generation still remain elusive.

To better understand the molecular mechanisms underlying IOS generation, stimulation-evoked IOS has been studied in various brain regions including the hippocampus and somatosensory cortex [8, 12-14]. Stimulation-evoked IOS is known to be dependent on postsynaptic glutamate receptors in the hippocampus [1, $15,16]$. We have also previously reported that neuronal activitydependent transient volume change by water influx through astrocytic aquaporin-4 (AQP4) entirely governs the IOS signal evoked by a $20 \mathrm{~Hz}$ stimulation of the Schaffer-collateral pathway in hippocampal slices as evidenced by the complete abolishment of IOS signal by gene-silencing of astrocytic AQP4 [17]. However, the detailed molecular mechanisms outlining what triggers the $20 \mathrm{~Hz}$ stimulation-induced water influx in astrocytes is still unknown.

To address this puzzling topic, we pharmacologically dissected the IOS under infrared wavelength in the stratum radiatum of the hippocampus evoked by a $20 \mathrm{~Hz}$ stimulation of the Schaffercollateral pathway and simultaneously measured the activity of the neuronal population with field potential recording to monitor neuronal activity-dependent transient volume changes in real time. We found that presynaptic voltage-gated $\mathrm{Na}^{+}$channels and $\mathrm{Ca}^{2+}$ channels, post-synaptic a-amino-3-hydroxy-5-methyl-4isoxazolepropionic acid (AMPA) and N-Methyl-D-aspartic acid or N-Methyl-D-aspartate (NMDA) receptors, and astrocytic $\mathrm{K}^{+}$ and $\mathrm{Cl}^{-}$channels are the key contributors to IOS by IOS's sensitivity to specific inhibitors: tetrodotoxin (TTX), cadmium $\left(\mathrm{Cd}^{2+}\right)$, 6-cyano-7-nitroquinoxaline-2,3-dione (CNQX), (2R)-amino5-phosphonovaleric acid (APV), quinine, and (5-Nitro-2-(3phenlypropylamino)benzoic acid) (NPPB).

\section{MATERIALS AND METHODS}

\section{Animals}

Adult (6 8 week) C57BL/6 (B6) mice of each sex were used. All mice were kept on a $12 \mathrm{~h} \mathrm{light-dark} \mathrm{cycle} \mathrm{in} \mathrm{a} \mathrm{specific-pathogen-}$ free facility with controlled temperature and humidity and had free access to food and water. All experimental procedures were conducted according to protocols approved by the directives of the Institutional Animal Care and Use Committee of KIST (Seoul, Republic of Korea, approval number: 2016-051).

\section{Slice preparation and electrophysiology}

Hippocampal slices were prepared as described previously [17]. Transverse slices containing hippocampus were sliced at a thickness of $300 \mu \mathrm{m}$ using a D.S.K Linear Slicer pro7 (Dosaka EM Co., Ltd, Japan). Slices were left to recover for at least $1 \mathrm{~h}$ before recording in an oxygenated $\left(95 \% \mathrm{O}_{2}\right.$ and $\left.5 \% \mathrm{CO}_{2}\right)$ preparation of aCSF containing (in mM): $130 \mathrm{NaCl}, 24 \mathrm{NaHCO}_{3}, 3.5 \mathrm{KCl}, 1.25$ $\mathrm{NaH}_{2} \mathrm{PO}_{4}, 1 \mathrm{CaCl}_{2}, 3 \mathrm{MgCl}_{2}$, and 10 glucose ( $\mathrm{pH}$ 7.4) at room temperature. After $1 \mathrm{~h}$, the preparation of aCSF was replaced with an oxygenated recording of aCSF solution $\left(1.5 \mathrm{CaCl}_{2}\right.$ and $1.5 \mathrm{MgCl}_{2}$ containing aCSF) which was also used when recording was performed.

Field potentials in the CA1 stratum radiatum evoked by Schaffer-collateral stimulation were measured as previously described [1] and responses were quantified in terms of field potential amplitude measurements. Recording was performed using a Multiclamp 700B amplifier (Molecular Devices). Data was acquired and analyzed with pClamp 10.2. Recording electrodes $(4 \sim 8 \mathrm{M} \Omega)$ were filled with $\mathrm{NaCl}(1 \mathrm{M})$.

\section{IOS imaging}

For IOS imaging devices, an infrared (IR) light source with optical filter (775 nm wavelength, Omega Filters) was used for transillumination of brain slices and these optical signals were obtained as IOS images from the stratum radiatum of the hippocampal CA1 region using a microscope (BX50WI, Olympus) equipped with a CCD camera (ORCA-R2, Hamamatsu). Imaging Workbench software (INDEC BioSystems, CA, USA) was used for image acquisition and analyses.

In detail, we first prepared mouse brain hippocampal slices (described in the methods for electrophysiology). Next, we fixed a hippocampal slice into the recording chamber and positioned the electrical stimulator in the CA1 stratum radiatum region. A series of 80 images/s were acquired following electrical stimulation (20 $\mathrm{Hz}, 1 \mathrm{~s}, 200 \sim 300 \bullet \mathrm{A})$. The relative change of transmittance $(\Delta \mathrm{T} / \mathrm{T})$ was normalized to baseline (average of 5 images). Decay of the IOS 
was measured by averaging the last $10 \mathrm{~s}$ of the response after dividing responses with peak response and adding baseline changes.

\section{Chemicals}

TTX citrate (tetrodotoxin citrate, Octahydro-12-(hydroxymethyl)-2-imino-5,9:7,10a-dimethano-10a $H$-[1,3] dioxocino[6,5d] pyrimidine-4,7,10,11,12-pentol citrate, Tocris, \#1069), $\mathrm{Cd}^{2+}$ (Cadmium sulfate hydrate, Sigma-Aldrich, \#25513), Concanamycin A (Folimycin, 3Z,5E,7R,8R,9S,10S,11R,13E, 15E, $17 S, 18 R)$ - 18 - [( $1 S, 2 R, 3 S)$-3 [(2R,4R,5S,6R)-4-[[4-O-(Aminocarbonyl)-2,6-dideoxy- $\beta$-D-arabino hexopyranosyl] oxy] tetrahydro-2-hydroxy-5-methyl-6-(1E)-1-propenyl-2H-pyran2-yl]-2-hydroxy-1-methylbutyl]-9-ethyl-8,10-dihydroxy-3,17dimethoxy-5,7,11,13-tetramethyloxacyclooctadeca-3,5,13,15tetraen-2-one, Sigma-Aldrich, \#C9705), APV (D-AP5, D-(-)2-Amino-5-phosphonopentanoic acid, Tocris, \#0106), CNQX (6-Cyano-7-nitroquinoxaline-2,3-dione, Tocris, \#0190), Bicuculline ((-)-Bicuculline methobromide, Tocris, \#0109), CGP-35348 ((3-Aminopropyl)(diethoxymethyl)phosphinic acid, Sigma-Aldrich, \#C5851), Strychnine ((-)-Strychnine, Strychnidin-10-one, Sigma-Aldrich, \#S0532), Suramin (Suramin sodium salt, SigmaAldrich, \#S2671), DL-TBOA (DL-threo-beta-Benzyloxyaspartate, Tocris, \#1223), Bumetanide (3-(Aminosulfonyl)-5-(butylamino)4-phenoxybenzoic acid, Sigma-Aldrich, \#B3023), $\mathrm{Ba}^{2+}$ (Barium chloride dihydrate, Sigma-Aldrich, \#529591), Furosemide (5-(Aminosulfonyl)-4-chloro-2-([2-furanylmethyl]amino)benzoic acid, Sigma-Aldrich, \#F4381), Ouabain (3-[(6-Deoxy- $\alpha$-Lmannopyranosyl)oxy]-1,5,11a,14,19-pentahydoxycard-20(22)enolide, Tocris, \#1076), Quinine ((R)-(6-Methoxyquinolin-4-yl) $((2 S, 4 S, 8 R)$ - 8-vinylquinuclidin-2-yl)methanol, Sigma-Aldrich, \# 145904), DCPIB (4-(2-butyl-6,7-dichloro-2-cyclopentylindan1-on-5-yl)oxybutyric acid, Tocris, \#1540), NPPB (5-Nitro-2-(3phenylpropyl-amino)benzoic acid, Sigma-Aldrich, \#N4779).

\section{Statistical analysis}

Statistical parameters including the exact value of $n$, the definition of center, dispersion and precision measures (mean \pm standard error of the mean (SEM)) and statistical significance are reported in the figures and figure legends. If the values come from a Gaussian distribution, all data points are tested by D'Agostino-Pearson omnibus normality test, and then appropriate statistical methods are applied. In figures, asterisks denote statistical significance as ${ }^{*} \mathrm{p}<0.05 ;{ }^{* *} \mathrm{p}<0.01 ;{ }^{* * *} \mathrm{p}<0.001 ;{ }^{* * * *} \mathrm{p}<0.000$, as well as nonsignificance with NS, $p>0.05$. Statistical analysis was performed in GraphPad PRISM 7 software.

\section{RESULTS}

\section{The neuronal activity-dependent light transmittance change is visualized using IOS imaging}

The neuronal activity-dependent IOS change can be observed with a fast rise (4 6s) followed by a slow decay (70 80 s) of light transmittance in the CA1 stratum radiatum of hippocampal slices upon electrical stimulation of the Schaffer collateral pathway for $1 \mathrm{~s}$ at $20 \mathrm{~Hz}$ as previously described [17] (Fig. 1A). Simultaneously, field excitatory post-synaptic potential (fEPSP) was measured to monitor the change in neuronal activity (Fig. 1A). To check the stimulation frequency-dependency of IOS, the IOS was measured with various stimulation frequencies from 1 to $100 \mathrm{~Hz}$ for $1 \mathrm{~s}$. The normalized IOS peak was gradually increased in a stimulation frequency-dependent manner with an $\mathrm{EC}_{50}$ at $20 \mathrm{~Hz}$ (Fig. $1 \mathrm{~B}$ and 1C). These results indicate that neuronal activity-dependent light transmittance change was visualized by IOS imaging.

\section{The presynaptic action potential and neurotransmitter re- lease are essential for the generation of activity-dependent IOSs and fEPSP}

Many previous studies have reported that the change of light scattering in brain slices originates from water movements in astrocytes according to excitatory synaptic transmission, resulting in the light transmittance change of IOS imaging $[1,11,12,14,16]$. Using various inhibitors of synaptic transmission, we characterized the synaptic nature of the IOS. To check the contribution of presynaptic neurons in the generation of activity-dependent IOS, we used TTX $(0.5 \mu \mathrm{M})$, a voltage-gated sodium channel blocker, and observed the complete abolishment of IOS peak, fEPSP, and fiber volley (Fig. 2A E), suggesting that presynaptic action potentials are essential for the generation of activity-dependent IOSs and fEPSPs. To further confirm the involvement of neurotransmitter release in the generation of activity-dependent IOS, we used $\mathrm{Cd}^{2+}(100 \mu \mathrm{M})$, an inhibitor for voltage-gated calcium channels, and Concanamycin A (ConA) $(0.5 \mu \mathrm{M}$, pre-treatment for $2 \mathrm{~h}$ ), an inhibitor for vacuolar type $\mathrm{H}^{+}$-ATPase in presynaptic vesicles. We found that $\mathrm{Cd}^{2+}$ and ConA significantly reduced IOSs and fEPSPs (Fig. $2 \mathrm{~F} \sim \mathrm{I}$, and $2 \mathrm{~K} \sim \mathrm{N}$ ), without affecting the fiber volley (Fig. $2 \mathrm{~J}$ and 2O). These results indicate that neurotransmitter release is also involved in the generation of activity-dependent IOS and fEPSP.

\section{Postsynaptic AMPA and NMDA receptors are major sources of activity-dependent IOS}

To determine the specific postsynaptic receptors for the generation of IOS, we considered various receptors for glutamate, GABA, 


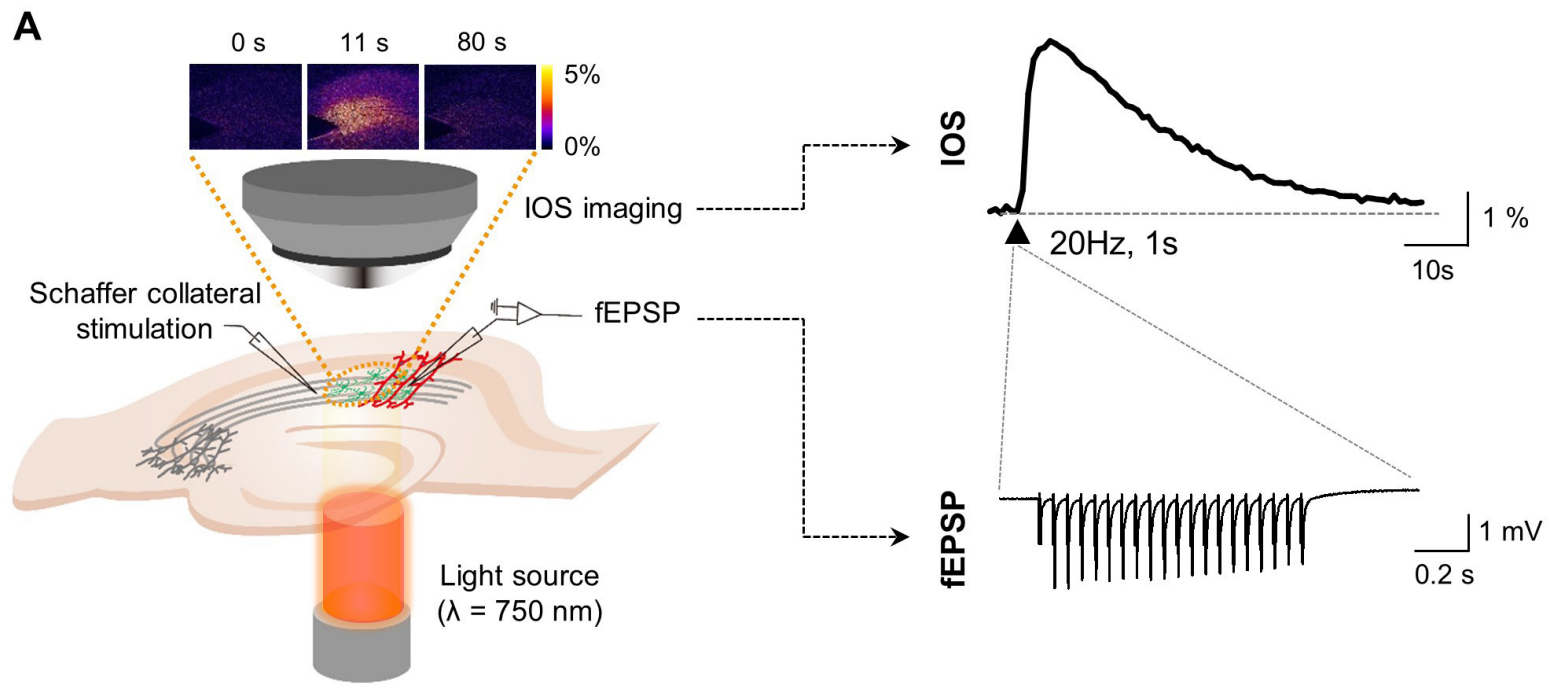

B

C

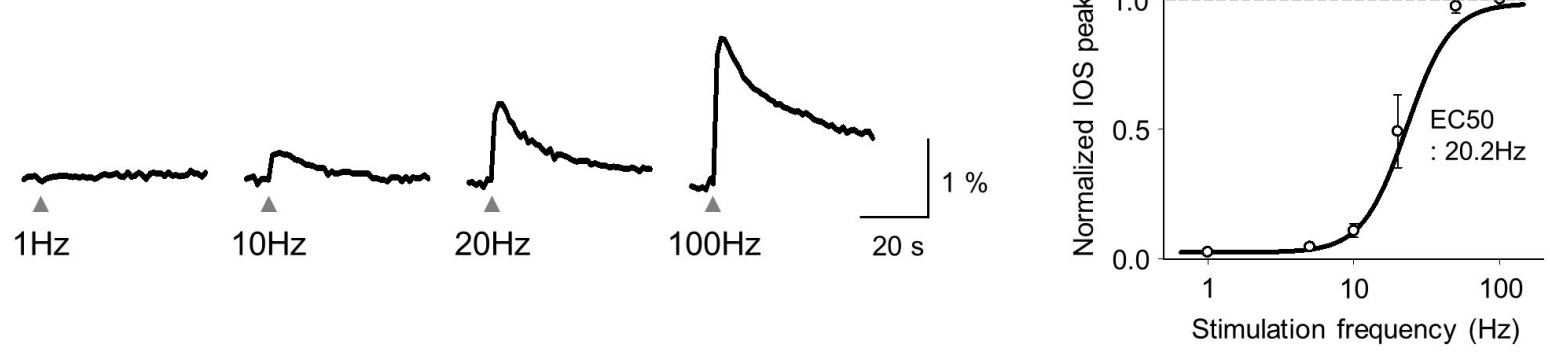

Fig. 1. Neuronal activity-dependent light transmittance change is visualized by the IOS imaging. (A) Schematic diagram. Simultaneous recording of IOS and fEPSP in the stratum radiatum region of the mouse hippocampus after stimulating the Schaffer Collateral pathway. Black triangle: stimulation. (B) Representative traces of IOS upon various stimulus intensities. (C) Normalized IOS peak curve upon various stimulus intensities.

glycine, and ATP expressed in CA1 pyramidal neurons as the putative candidates [18, 19] (Fig. 3A). We found a significant reduction in IOS peak, abolishment of fEPSP, and intact fiber volley by APV $(50 \mu \mathrm{M})$ and CNQX $(20 \mu \mathrm{M})$ (Fig. 3B E). However, the IOS peak was not changed by inhibitors for $\mathrm{GABA}_{\mathrm{A}}$ and $\mathrm{GABA}_{\mathrm{B}}$ receptors (bicuculline, $10 \mu \mathrm{M}$, and CGP-35348, $5 \mu \mathrm{M}$, Fig. 3F and 3G), even in the presence of inhibitors for glutamate receptors (APV and CNQX) (Fig. 3H and 3I). To determine if other neurotransmitters and their receptors are involved in the generation of IOS, we treated the inhibitors for glycine (strychnine, $1 \mu \mathrm{M}$ ) and ATP (suramin, $100 \mu \mathrm{M})$ receptors in the presence of APV and CNQX. However, we found no further inhibition of IOS peak by strychnine and suramin (Fig. 3J M). These data suggest that activity-dependent IOS is mostly generated by excitatory synaptic transmission via postsynaptic glutamate receptors, including AMPA and NMDA receptors, rather than by other transmitters and receptors, such as

\section{GABA, glycine, and ATP.}

To determine the relative contribution of each step during synaptic transmission, the IOS peak after treatment of various drugs, such as APV and CNQX, TTX, $\mathrm{Cd}^{2+}$, and ConA, were normalized by the peak of the control IOS (Fig. $3 \mathrm{~N}$ ). There was $5.8 \%$ of the TTX insensitive portion, and a $54.9 \%$ contribution of the postsynaptic glutamate receptor as evidenced by block percent of APV and CNQX. The contribution of action potential (AP) firing as $11.7 \%$, vesicle fusion as $27.7 \%$ including $23.6 \%$ of RRP (readily releasable pool) vesicle fusion and $4.1 \%$ of empty vesicle fusion were calculated by taking the difference of block-percentage of $\mathrm{Cd} 2+$ from TTX, ConA from $\mathrm{Cd}^{2+}$, and APV and CNQX from ConA, respectively (Fig. $3 \mathrm{~N}$ and $3 \mathrm{O}$ ). 

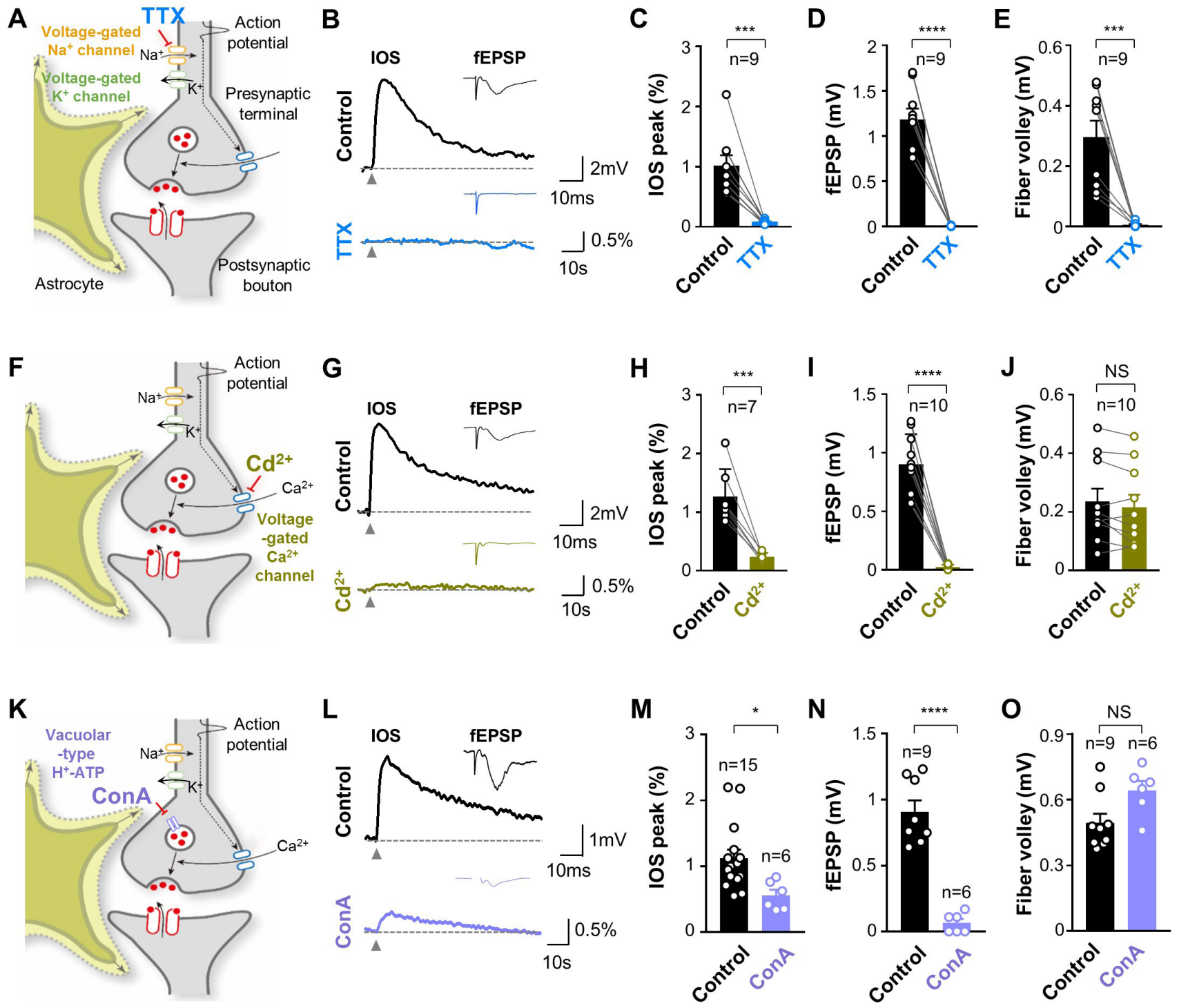

Fig. 2. Presynaptic action potential and neurotransmitter release are essential for the generation of activity-dependent IOS and fEPSP. (A, F, K) Schematic diagram for contribution of pre-synaptic action potential and neurotransmitter release. (B, G, L) Representative traces of IOS. Inset: Representative traces of fEPSP. (C, H, M) The percentage of IOS peak. (D, I, N) fEPSP amplitude (mV). (E, J, O) fiber volley of fEPSP (mV). ((C to J) paired t-test (twotailed), (M to O) unpaired t-test (two-tailed), ${ }^{* * *} \mathrm{p}<0.001,{ }^{* * * *} \mathrm{p}<0.0001, \mathrm{NS} \mathrm{p}>0.05$ ).

The increase of both extracellular $K^{+}$and glutamate during excitatory synaptic transmission could be the remaining sources of activity-dependent IOS

We confirmed that presynaptic release of glutamate and postsynaptic activation of the glutamate receptor are the main sources of IOSs (Fig. 3O). This finding raised the possibility that the extracellular glutamate and $\mathrm{K}^{+}$resulting from excitatory synaptic transmission could be detected by IOS (Fig. 4A). To test this idea, we treated the glutamate $(10 \mathrm{mM})$ and $\mathrm{K}^{+}(5 \mathrm{mM})$ in a $4 \%$ agarose gel to mimic the brain slice and avoid the excitotoxicity that occurs in real brain slices (Fig. 4B). It has been reported that electri- cal stimulation in the hippocampus induces millimolar changes in glutamate [20] and $\mathrm{K}^{+}$[21]. Interestingly, we found that IOS change by treatment of glutamate and $\mathrm{K}^{+}$in agarose gel (Fig. $4 \mathrm{C}$ and $4 \mathrm{D})$, suggesting the extracellular ionic concentration changes as a source of IOS.

Astrocytes rapidly take-up glutamate resulting from presynaptic glutamate release during synaptic transmission via glutamate transporters, mostly expressed in astrocytes [22]. Recently, the astrocytic glutamate transporter EAAT2 has been reported to contribute to IOS as evidenced by a significant inhibition of IOS by dihydrokainic acid (DHK), an inhibitor for glutamate transporter 
A

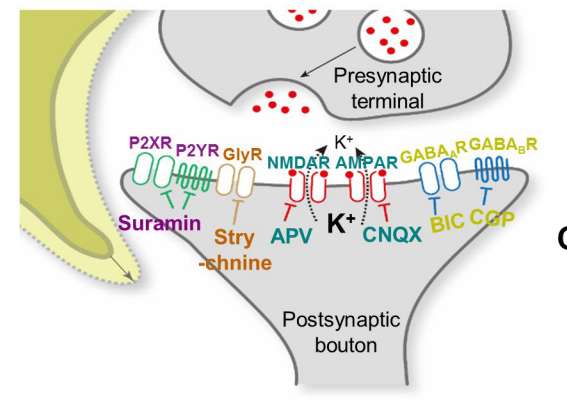

$\mathbf{F}$

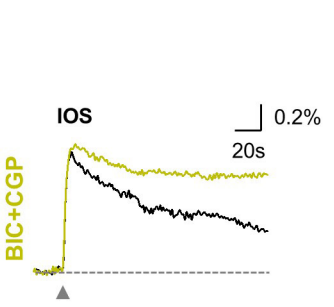

J

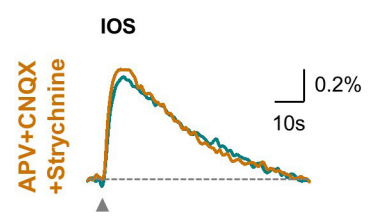

$\mathbf{N}$

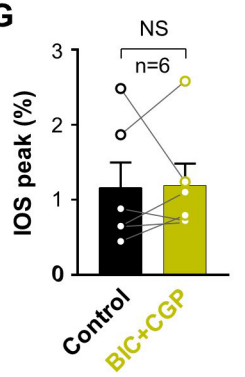

K

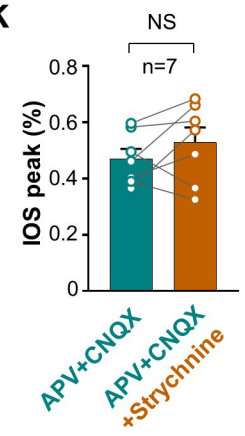

B

C

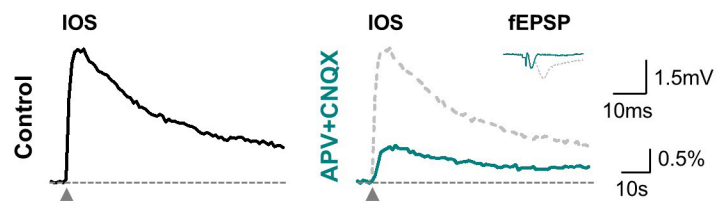

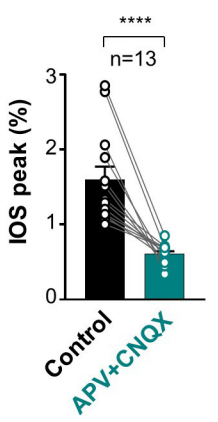

H

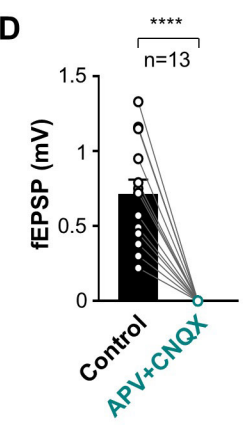

E

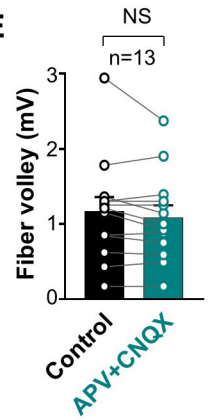

I

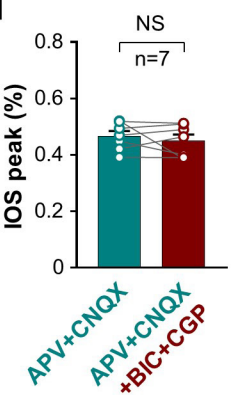

$\mathbf{L}$

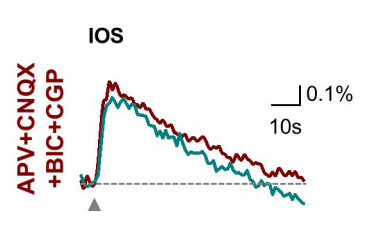

M
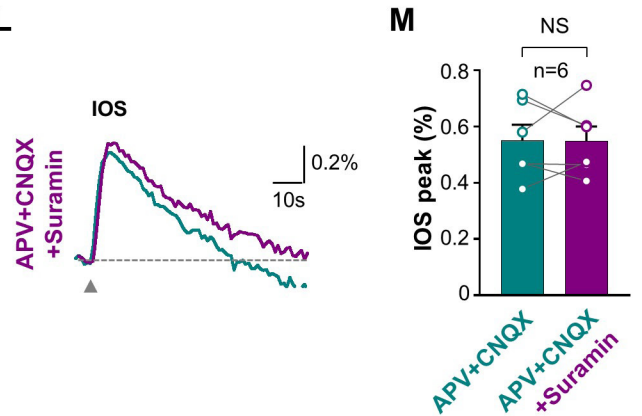

0

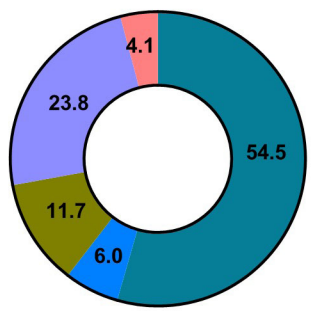

Post

TTX-insensitive

AP firing

RRP vesicle fusion

Empty vesicle fusion

Post: APV CNQX sensitive

AP firing: TTX $-\mathrm{Cd}^{2+}$

RRP fusion: $\mathrm{Cd}^{2+}-\mathrm{Con} A$

Total fusion: $\mathrm{Cd}^{2+}-\mathrm{APV} \& \mathrm{CNQX}$

Empty fusion: Total - RRP fusion

Fig. 3. Postsynaptic AMPA and NMDA receptors are the major sources of the activity-dependent IOS. (A) Schematic diagram for candidates of postsynaptic receptors as the sources of IOS. (B, F, H, J, L) Representative traces of IOS. Inset: Representative traces of fEPSP. (C, G, I, K, M) The percentage of IOS peak. (D, E) fEPSP amplitude (mV), and fiber volley $(\mathrm{mV})$. ((C to M) paired t-test (two-tailed), $\left.{ }^{*} \mathrm{p}<0.05,{ }^{* *} \mathrm{p}<0.01,{ }^{* * *} \mathrm{p}<0.001, \mathrm{NS} \mathrm{p}>0.05\right)$. (N) Summary bar graph of the normalized percentage of IOS peak. (O) Summary pie chart of the contribution percentage for IOS peak. (Post: APV and CNQXsensitive portion of IOS peak, TTX-insensitive: TTX-insensitive portion of IOS peak, AP firing: subtracting $\mathrm{Cd}^{2+}$ from TTX-sensitive portion of IOS peak, RRP vesicle fusion: Concanamycin A from $\mathrm{Cd}^{2+}$-sensitive portion of IOS peak, Empty vesicle fusion: APV and CNQX from Concanamycin Asensitive portion of IOS peak). 
A

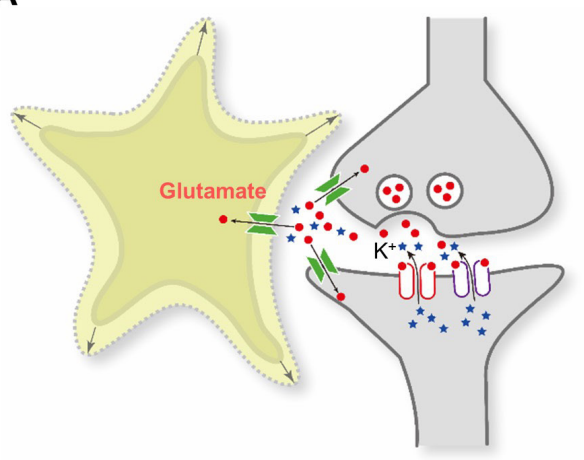

C

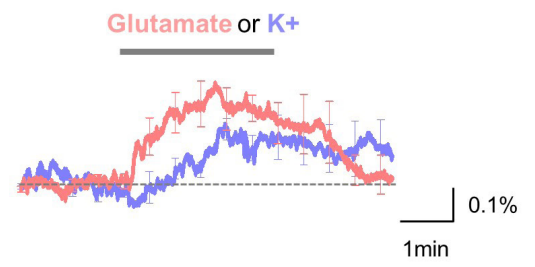

B

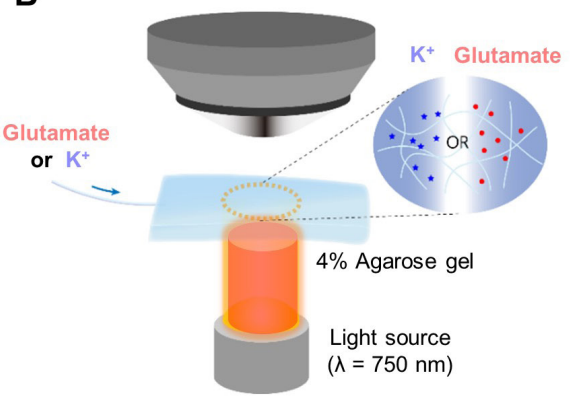

D

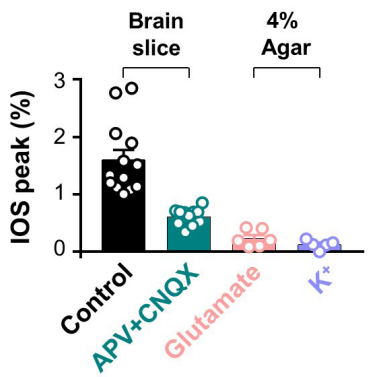

E

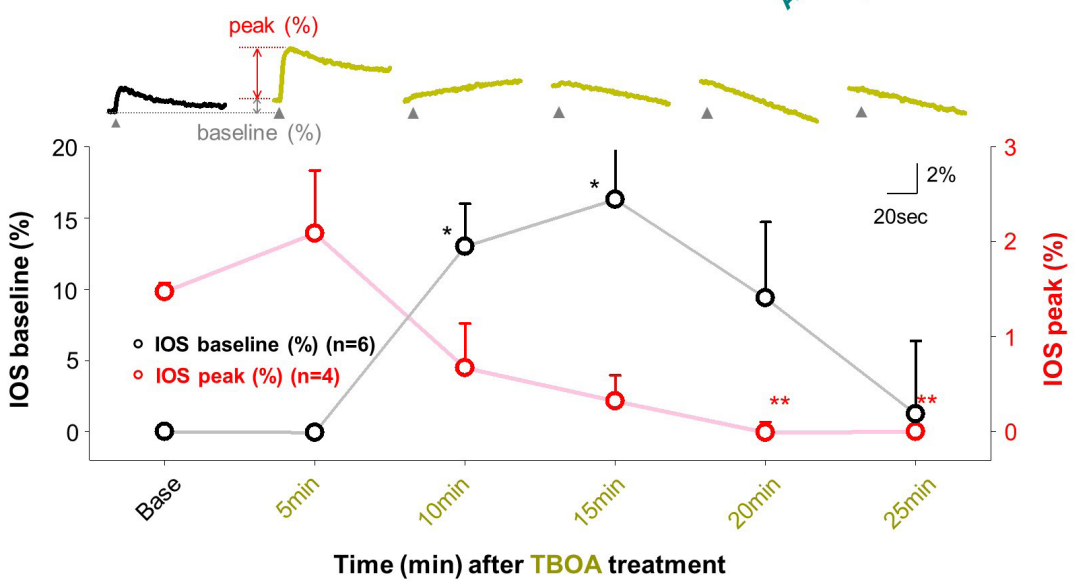

$\mathbf{F}$
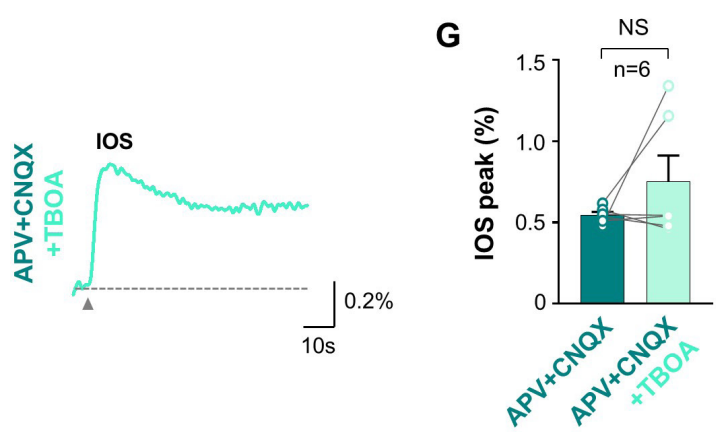

Fig. 4. Extracellular ionic concentration changes in glutamate and $\mathrm{K}^{+}$contribute to activity-dependent IOS. (A) Schematic diagram of extracellular glutamate and $\mathrm{K}+$ change during excitatory synaptic. (B) Schematic diagram of experiments on $4 \%$ agarose gel with glutamate $(10 \mathrm{mM})$ and $\mathrm{K}^{+}(5 \mathrm{mM})$. (C) Averaged IOS traces on 4\% agarose gel with glutamate and $\mathrm{K}^{+}$. (D) Summary bar graph showing electrical stimulation-evoked IOS peak percentage in brain slice after APV and CNQX treatment and bath application of either glutamate or $\mathrm{K}^{+}$-evoked IOS peak percentage in $4 \%$ agarose gel. (E) Representative IOS traces (top) and changes in IOS baseline and peak (bottom) in the presence of TBOA by applying repetitive stimulation within a 5 min interval. (F, G) Representative IOS traces and percentage of IOS peak by treatment of TBOA with APV and CNQX compared to APV and CNQX without TBOA (paired t-test (two-tailed), NS p $>0.05$ ). 
A

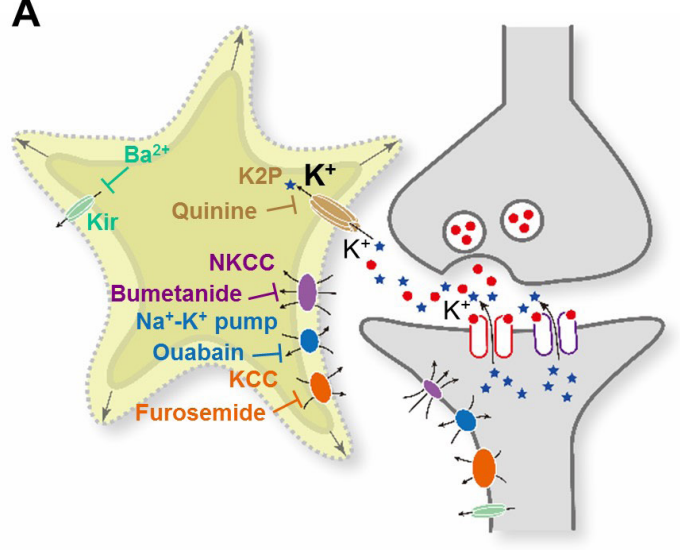

B

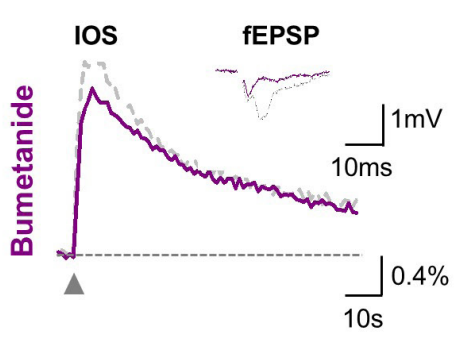

E

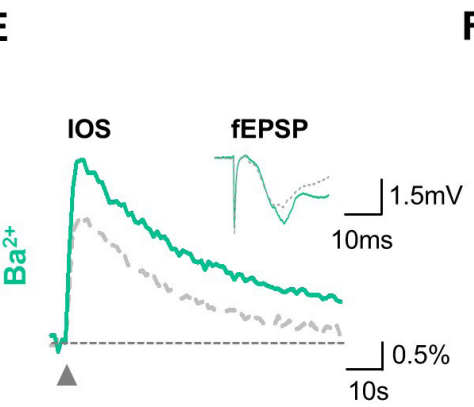

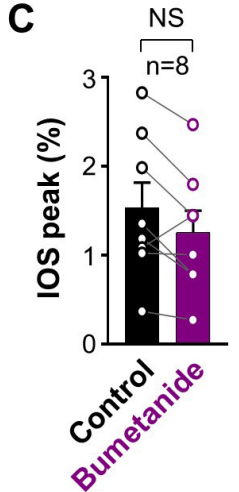

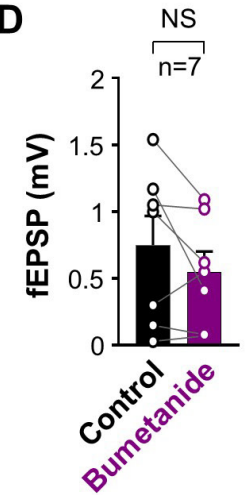

$\mathbf{F}$

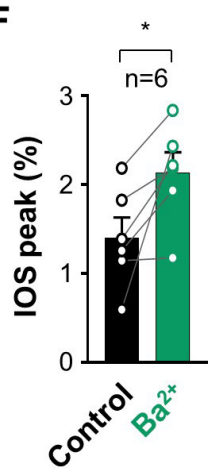

G

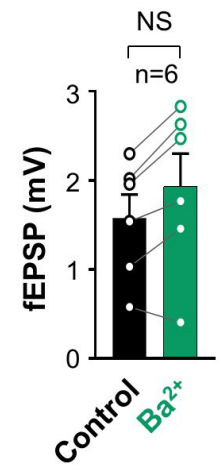

H

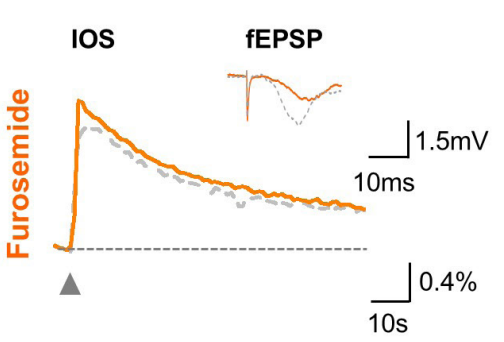

$\mathbf{K}$
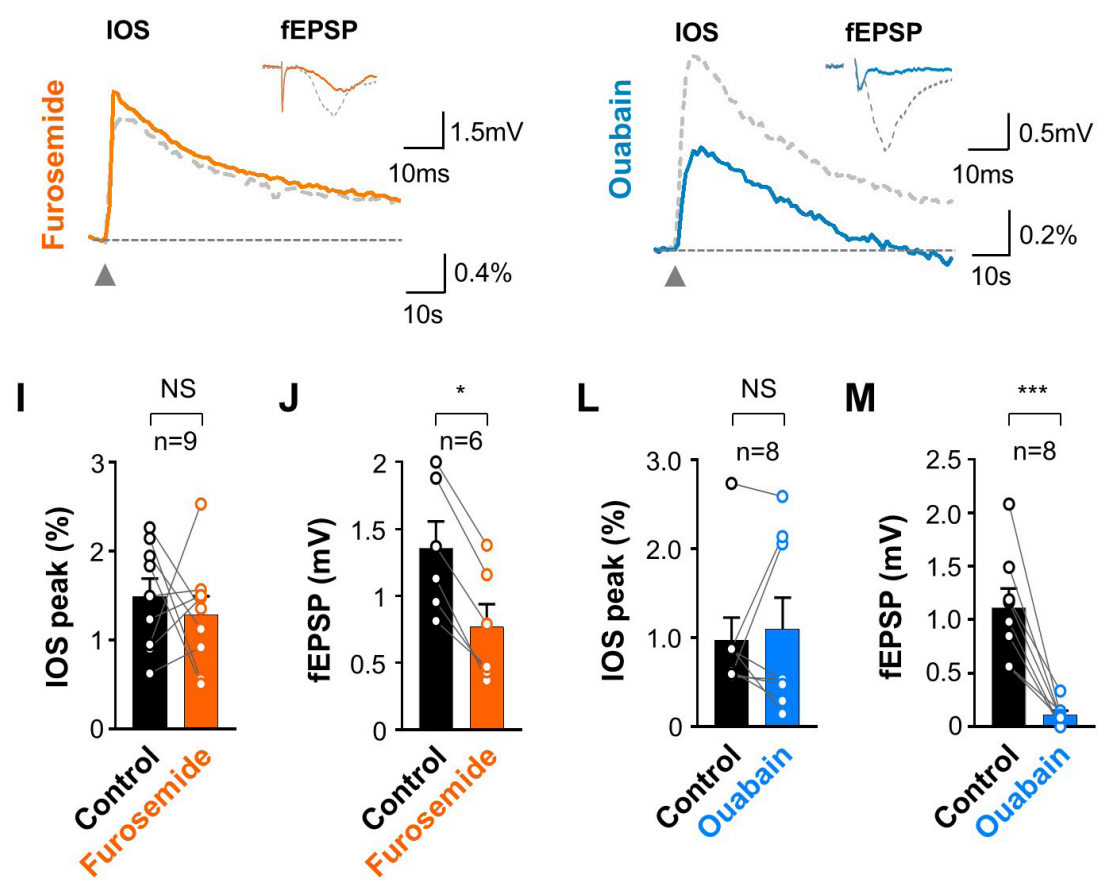

$\mathbf{N}$

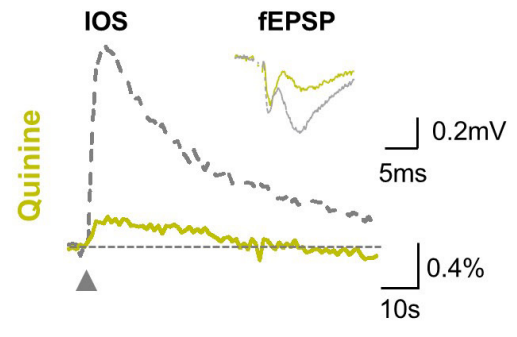

Fig. 5. Quinine-sensitive K2P channel is the best candidate for the astrocytic $\mathrm{K}^{+}$uptake as the main source of activity-dependent IOS. (A) Schematic diagram of the source of $\mathrm{K}^{+}$uptake. (B, E, H, K, N) Representative traces of IOS. Inset: Representative traces of fEPSP. (C, F, I, L, O) The percentage of IOS peak (paired t-test (two-tailed), ${ }^{*} \mathrm{p}<0.05,{ }^{* * *} \mathrm{p}<0.001$, NS $\mathrm{p}>0.05$ ). (D, G, J, M, P) The amplitude of fEPSP (mV) (paired t-test (two-tailed), ${ }^{*} \mathrm{p}<0.05$, $\left.{ }^{* *} \mathrm{p}<0.01,{ }^{* * *} \mathrm{p}<0.001, \mathrm{NS} \mathrm{p}>0.05\right)$. 
A
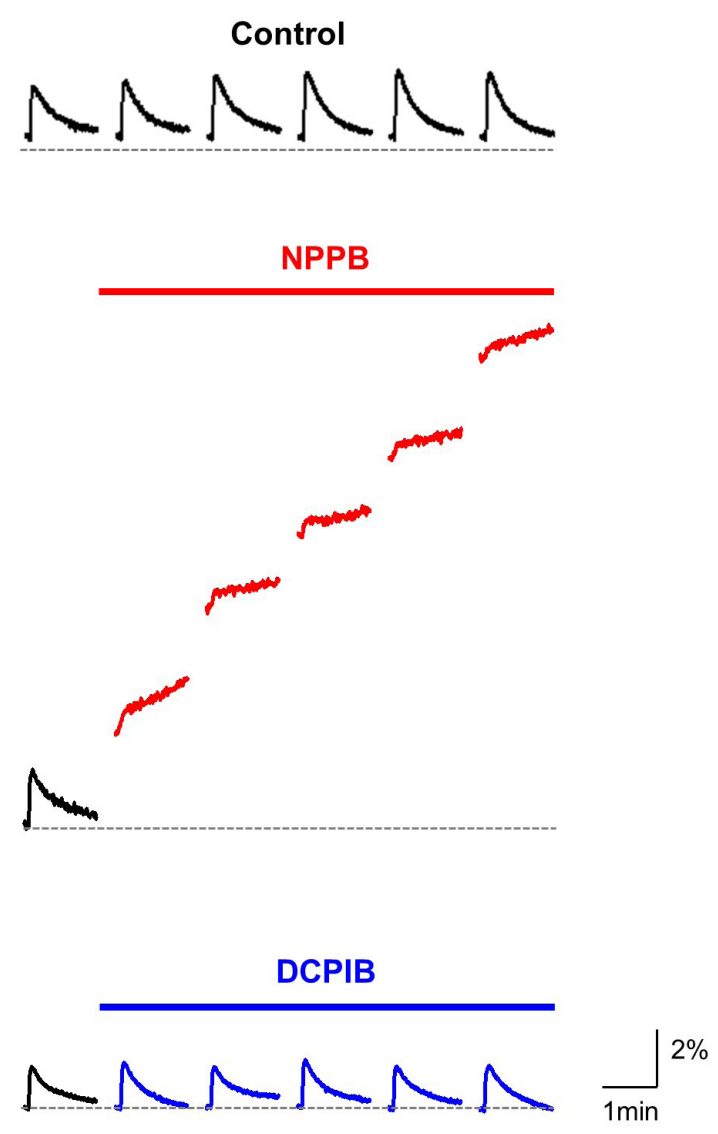

B
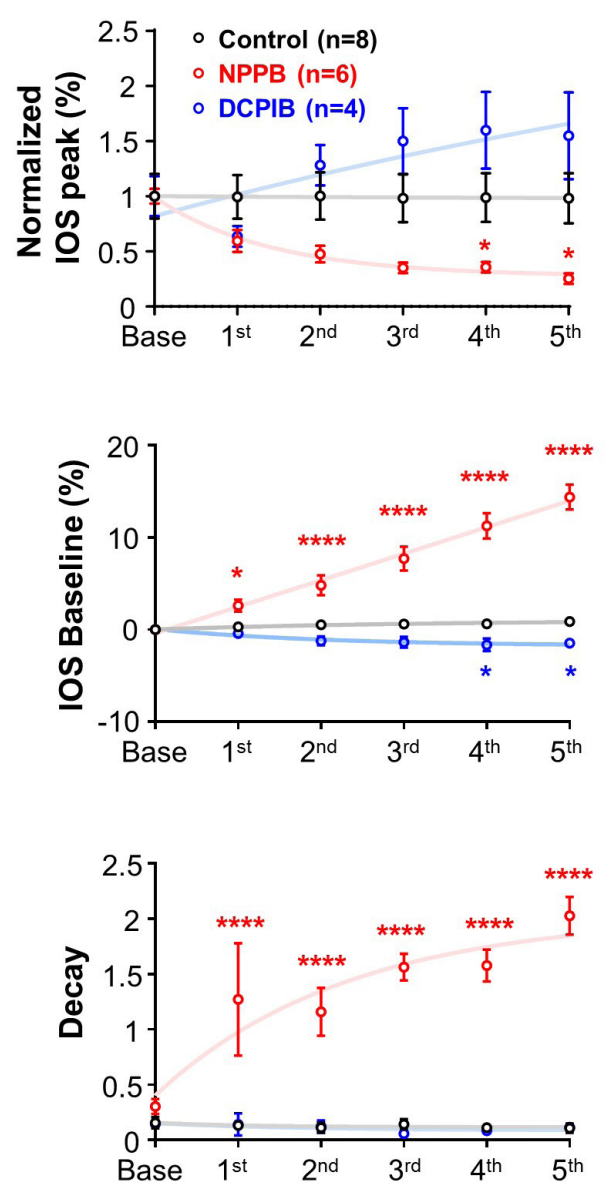
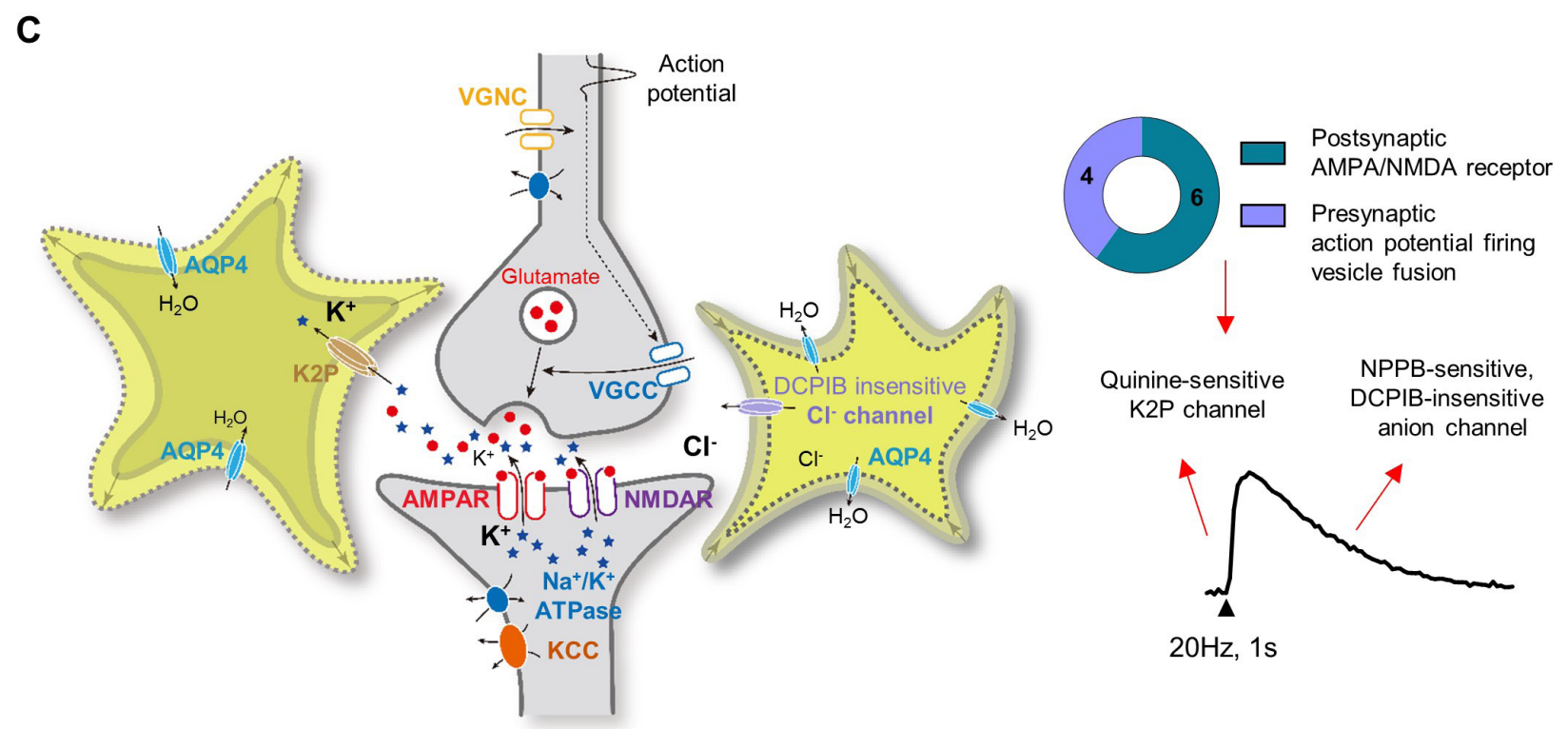
Quinine-sensitive NPPB-sensitive, K2P channel DCPIB-insensitive

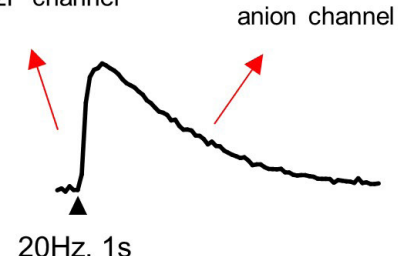

$20 \mathrm{~Hz}, 1 \mathrm{~s}$

Fig. 6. DCPIB -insensitive anion channel is the best candidate for the extrusion of anions in astrocytes as the main source of the activity-dependent IOS decay. (A) Representative IOS traces in the presence of NPPB and DCPIB by applying repetitive stimulation within a 5 min interval. (B) The percentage of peak (top), baseline (middle), and decay (bottom) changes of IOS normalized to control value. (C) Summary of schematic diagram. 
EAAT2 [16, 23]. However, a long-term treatment with glutamate transporter inhibitors could cause an undesirable side-effects such as desensitization of glutamate receptors such as AMPA, kainate, and NMDA receptors by accumulated glutamate at the synaptic junctions, giving rise to a misinterpretation of the results. Therefore, to test the precise contribution of glutamate uptake in IOS generation, we applied TBOA $(100 \mu \mathrm{M})$, a non-selective glutamate transporter inhibitor to brain slices and monitored IOS upon repetitive stimulations for a long-period of time. Interestingly, TBOA initially increased the amplitude of IOS upon first stimulation, but then significantly decreased the amplitude upon following repetitive stimulations (Fig. 4E). These two different responses seem to be caused by further activation and desensitization of postsynaptic glutamate receptors including AMPA and NMDA receptors in response to accumulated extracellular glutamate. In contrast, the baseline IOS was increased from 10 min after treatment of TBOA, sustained, and suddenly decreased following stimulations (Fig. $4 \mathrm{E})$. This baseline change might be caused by slower glutamate accumulation and diffusion in the extracellular space. It was difficult to interpret the involvement of glutamate uptake via transporter in IOS generation, which might be due to side effects such as desensitization of glutamate receptors by TBOA. To solve this issue, we administered the TBOA in the presence of APV and CNQX. However, we did not find any significant difference in IOS peak between before and during TBOA applications (Fig. 4F and 4G), indicating that there is no direct involvement of glutamate uptake in IOS generation.

\section{Quinine-sensitive K2P channel mediates the astrocytic $K^{+}$ uptake as the main source of activity-dependent IOS}

Astrocytes govern extracellular $\mathrm{K}^{+}$uptake, $\mathrm{K}^{+}$buffering, or $\mathrm{K}^{+}$ clearance to maintain the extracellular $\mathrm{K}^{+}$concentration. Previously, many $\mathrm{K}^{+}$channels or transporters including $\mathrm{Na}-\mathrm{K}-\mathrm{Cl}$ cotransporter (NKCC1), inward-rectifier $\mathrm{K}^{+}$channel subtype (Kir4.1), K-Cl cotransporter (KCC2), $\mathrm{Na}^{+} / \mathrm{K}^{+}$-ATPase $\left(\mathrm{Na}^{+} / \mathrm{K}^{+}\right.$ pump), and two-pore-domain $\mathrm{K}^{+}$channels (K2P) have been proposed as the molecular targets for $\mathrm{K}^{+}$buffering in astrocytes [21, 24-28]. We tested these various molecular candidates for $\mathrm{K}^{+}$uptake using pharmacological tools (Fig. 5A). We found no significant inhibition of IOS peak by inhibitors for NKCC1 (bumetanide, $10 \mu \mathrm{M})$, Kir4.1 ( $\left.\mathrm{Ba}^{2+}, 100 \mu \mathrm{M}\right), \mathrm{KCC} 2$ (Furosemide, $3 \mathrm{mM}$ ), and $\mathrm{Na}^{+} / \mathrm{K}^{+}$pump (ouabain, $100 \mu \mathrm{M}$ ) (Fig. 5B J). For the last candidate, we considered two-pore domain $\mathrm{K}^{+}$channels, K2P, which have been known to majorly contribute to background leaking $\mathrm{K}^{+}$current, or "passive conductance" in astrocytes $[29,30]$. To test the involvement of $\mathrm{K} 2 \mathrm{P}$ channels for the source of $\mathrm{K}^{+}$uptake, we used quinine, an inhibitor of the K2P channel. Despite decreases in fEPSP by quinine, quinine significantly inhibited the IOS peak (Fig. $5 \mathrm{~N} \sim \mathrm{P}$ ). These results indicate that the K2P channel mediates astrocytic volume change through $\mathrm{K}^{+}$uptake rather than NKCC1, Kir4.1, KCC2, or the $\mathrm{Na}^{+} / \mathrm{K}^{+}$pump.

\section{DCPIB-insensitive anion channels mediate the extrusion} of anions in astrocytes as the main source of the activitydependent IOS decay

Next, we explored the molecular mechanisms of the volume decrease following $\mathrm{K}^{+}$uptake. Many previous studies have reported that the regulatory volume decrease is mediated by the extrusion of anions via volume-regulated anion channel (VRAC) [31, 32]. The molecular identity which governs the volume decrease following $\mathrm{K}^{+}$uptake has yet to be established. Therefore, we first investigated the possible involvement of anion channels using the general anion channel blocker, NPPB $(50 \mu \mathrm{M})$. NPPB increased the baseline and eliminated the decay of IOS, an indication of the inhibition of a volume decrease, upon repetitive stimulations. However, DCPIB, a specific inhibitor for VRAC [33], did not affect these (Fig. 6A and 6B). These results suggest that the volume decrease is mediated by DCPIB-insensitive anion channels.

Taken together, the sources of activity-dependent IOS mostly originate from postsynaptic glutamate receptors, including AMPA and NMDA receptors, but not from GABA, ATP, and Glycine receptors. Our results further reveal that both extracellular glutamate and $\mathrm{K}^{+}$are taken up by astrocytes near the synapse during synaptic transmission. Furthermore, we found that the decay of IOS is mediated by the DCPIB-insensitive anion channels expressed in astrocytes (Fig. 6C). Our results demonstrated that the functional coupling between synaptic activity and astrocytic volume transient in hippocampal slices during excitatory synaptic transmission are the major source of IOS imaging.

\section{DISCUSSION}

In the present study, we used pharmacological dissection to demonstrate that IOS indicating the neuronal activity-dependent astrocytic volume change originates from excitatory synaptic transmission through postsynaptic glutamate receptor activation, presynaptic action potential, and extracellular ionic concentration change. Although previous studies attempted to describe the origin of IOS as postsynaptic glutamate receptors $[1,16]$, we have extensively determined the origin of IOS in terms of the rise and decay kinetics and linked with possible molecular mechanisms using pharmacological agents. We have demonstrated that the rise of IOS is mediated by the K2P channel, whereas the decay of IOS is mediated by DCPIB-insensitive anion channels in astrocytes (Fig. 
6C).

In agreement with previous findings that IOS is mostly mediated by postsynaptic glutamate receptor activation $[1,16]$, we also confirmed that about $54.5 \%$ of the IOS peak was blocked by APV and CNQX (Fig. 3O). In contrast to previous reports [16, 23], we found no contribution of glutamate transporters (Fig. $4 \mathrm{~F}$ and $4 \mathrm{G}$ ) and the apparent contribution upon long-term treatment by inhibitors such as DHK and TBOA was due to an undesirable sideeffect such as desensitization of postsynaptic glutamate receptors. With additional treatment of receptor blockers for GABA, glycine, and ATP, we found that the remaining $45.5 \%$ of IOS did not originate from these receptors (Fig. 3F M). Then, we hypothesized that presynaptic neurons and extracellular ionic concentrations themselves could be contributing to the remaining IOS peak. Interestingly, we found that $27.9 \%$ and $11.7 \%$ of IOS originated from presynaptic vesicle fusion and action potential firing, respectively, which are determined by subtracting APV and CNQX from $\mathrm{Cd}^{2+}$ and $\mathrm{Cd}^{2+}$ from TTX-sensitive IOS (Fig. 2L and 2M). Furthermore, we found changes in IOS due to glutamate or $\mathrm{K}^{+}$in $4 \%$ agarose gel (Fig. $4 \mathrm{~B}$ and $4 \mathrm{C}$ ), suggesting the further contribution of extracellular ambient glutamate and $\mathrm{K}^{+}$during excitatory synaptic transmission. Through these experiments, we fully dissected the origin of IOS.

Astrocytes maintain proper ionic concentrations in extracellular spaces, for example, by taking up $\mathrm{K}^{+}$and releasing chloride ions $\left(\mathrm{Cl}^{-}\right)$during synaptic transmission $[31,34]$. During this process, the water moves in and out from the astrocytes to solve osmotic pressure through AQP4, resulting in volume transients [14, 34, 35]. Although many studies have suggested the molecular mechanism for these processes over the decades, controversies remain. Here, we found that the K2P channel mediates astrocytic volume increase through $\mathrm{K}^{+}$uptake rather than NKCC1, Kir4.1, KCC2, or the $\mathrm{Na}^{+} / \mathrm{K}^{+}$pump (Fig. 5). Also, we found that the DCPIBinsensitive anion channel mediates astrocytic volume decreases through anion extrusion rather than VRAC (Fig. 6A and 6B). With these striking findings, we strongly suggest the novel molecular mechanism for astrocytic volume change. However, we measured the volume transient using IOS rather than ionic $\left(\mathrm{K}^{+}\right.$and $\left.\mathrm{Cl}^{-}\right)$ movements. Further studies are required for direct measurement of $\mathrm{K}^{+}$uptake and $\mathrm{Cl}^{-}$efflux in astrocytes during volume transient. Furthermore, there will be an instantaneous accumulation of positive charges in astrocytes as the result of $\mathrm{K}^{+}$uptake and $\mathrm{Cl}^{-}$efflux during volume transient. There should be ionic movement with counter charges against $\mathrm{K}^{+}$and $\mathrm{Cl}^{-}$to prevent excessive depolarization in astrocytes. Further studies are required to address this issue. Many previous studies, including ours, have revealed that activity-dependent astrocytic transient volume change via AQP4 is required for synaptic plasticity and learning, especially language learning $[17,36]$. In addition, K2P channel-mediated $\mathrm{K}^{+}$uptake and NPPB-sensitive, DCPIB-insensitive $\mathrm{Cl}^{-}$channel-mediated $\mathrm{Cl}^{-}$efflux are potential molecular candidates for IOS generation and could also participate in synaptic plasticity and learning. The synaptic plasticity could be simply measured by the IOS imaging instead of fEPSP or whole-cell patch-clamp recording. For example, the IOS peak could be increased or decreased after stimulating schaffer-collateral pathway with the induction protocols for LTP or LTD. Therefore, future study to elucidate the functional role of activity-dependent transient volume change, which could be linked with synaptic plasticity and learning, are needed.

In summary, our study identified the astrocytic K2P channels and NPPB-sensitive anion channel as the origin and source of neuronal activity-dependent IOS during volume transient using pharmacological dissection, thereby helping us to understand the fundamental role of astrocytes in terms of ionic homeostasis during synaptic transmission.

\section{ACKNOWLEDGEMENTS}

This study was supported by the Creative Research Initiative Program, Korean National Research Foundation (2015R1A3A2066619), and IBS institutional Grant (IBS-R001D1). J.Woo and Y.Han contributed equally to this work.

\section{REFERENCES}

1. MacVicar BA, Hochman D (1991) Imaging of synaptically evoked intrinsic optical signals in hippocampal slices. J Neurosci 11:1458-1469.

2. Zepeda A, Arias C, Sengpiel F (2004) Optical imaging of intrinsic signals: recent developments in the methodology and its applications. J Neurosci Methods 136:1-21.

3. Gurden H, Uchida N, Mainen ZF (2006) Sensory-evoked intrinsic optical signals in the olfactory bulb are coupled to glutamate release and uptake. Neuron 52:335-345.

4. Pouratian N, Cannestra AF, Martin NA, Toga AW (2002) Intraoperative optical intrinsic signal imaging: a clinical tool for functional brain mapping. Neurosurg Focus 13:e1.

5. Rector DM, Poe GR, Kristensen MP, Harper RM (1997) Light scattering changes follow evoked potentials from hippocampal Schaeffer collateral stimulation. J Neurophysiol 78:17071713.

6. Frostig RD, Lieke EE, Ts'o DY, Grinvald A (1990) Cortical functional architecture and local coupling between neuronal activity and the microcirculation revealed by in vivo high- 
resolution optical imaging of intrinsic signals. Proc Natl Acad Sci U S A 87:6082-6086.

7. Malonek D, Grinvald A (1996) Interactions between electrical activity and cortical microcirculation revealed by imaging spectroscopy: implications for functional brain mapping. Science 272:551-554.

8. Aitken PG, Fayuk D, Somjen GG, Turner DA (1999) Use of intrinsic optical signals to monitor physiological changes in brain tissue slices. Methods 18:91-103.

9. Narayan SM, Santori EM, Toga AW (1994) Mapping functional activity in rodent cortex using optical intrinsic signals. Cereb Cortex 4:195-204.

10. Mané M, Müller M (2012) Temporo-spectral imaging of intrinsic optical signals during hypoxia-induced spreading depression-like depolarization. PLoS One 7:e43981.

11. Holthoff K, Witte OW (1996) Intrinsic optical signals in rat neocortical slices measured with near-infrared dark-field microscopy reveal changes in extracellular space. J Neurosci 16:2740-2749.

12. Cerne R, Haglund MM (2002) Electrophysiological correlates to the intrinsic optical signal in the rat neocortical slice. Neurosci Lett 317:147-150.

13. Syková E, Vargová L, Kubinová S, Jendelová P, Chvátal A (2003) The relationship between changes in intrinsic optical signals and cell swelling in rat spinal cord slices. Neuroimage 18:214-230.

14. Kitaura H, Tsujita M, Huber VJ, Kakita A, Shibuki K, Sakimura K, Kwee IL, Nakada T (2009) Activity-dependent glial swelling is impaired in aquaporin- 4 knockout mice. Neurosci Res 64:208-212.

15. MacVicar BA, Feighan D, Brown A, Ransom B (2002) Intrinsic optical signals in the rat optic nerve: role for $\mathrm{K}(+)$ uptake via NKCC1 and swelling of astrocytes. Glia 37:114-123.

16. Pál I, Nyitrai G, Kardos J, Héja L (2013) Neuronal and astroglial correlates underlying spatiotemporal intrinsic optical signal in the rat hippocampal slice. PLoS One 8:e57694.

17. Woo J, Kim JE, Im JJ, Lee J, Jeong HS, Park S, Jung SY, An H, Yoon S, Lim SM, Lee S, Ma J, Shin EY, Han YE, Kim B, Lee EH, Feng L, Chun H, Yoon BE, Kang I, Dager SR, Lyoo IK, Lee CJ (2018) Astrocytic water channel aquaporin-4 modulates brain plasticity in both mice and humans: a potential gliogenetic mechanism underlying language-associated learning. Mol Psychiatry 23:1021-1030.

18. Keck T, White JA (2009) Glycinergic inhibition in the hippocampus. Rev Neurosci 20:13-22.

19. Wieraszko A, Goldsmith G, Seyfried TN (1989) Stimulationdependent release of adenosine triphosphate from hippo- campal slices. Brain Res 485:244-250.

20. Medina-Ceja L, Pardo-Peña K, Morales-Villagrán A, OrtegaIbarra J, López-Pérez S (2015) Increase in the extracellular glutamate level during seizures and electrical stimulation determined using a high temporal resolution technique. BMC Neurosci 16:11.

21. Larsen BR, Assentoft M, Cotrina ML, Hua SZ, Nedergaard M, Kaila K, Voipio J, MacAulay N (2014) Contributions of the $\mathrm{Na}^{+} / \mathrm{K}^{+}$-ATPase, $\mathrm{NKCC1}$, and Kir4.1 to hippocampal $\mathrm{K}^{+}$ clearance and volume responses. Glia 62:608-622.

22. Anderson CM, Swanson RA (2000) Astrocyte glutamate transport: review of properties, regulation, and physiological functions. Glia 32:1-14.

23. Pál I, Kardos J, Dobolyi Á, Héja L (2015) Appearance of fast astrocytic component in voltage-sensitive dye imaging of neural activity. Mol Brain 8:35.

24. Su G, Kintner DB, Sun D (2002) Contribution of $\mathrm{Na}(+)$ $\mathrm{K}(+)-\mathrm{Cl}(-)$ cotransporter to high- $[\mathrm{K}(+)](\mathrm{o})$ - induced swelling and EAA release in astrocytes. Am J Physiol Cell Physiol 282:C1136-C1146.

25. Djukic B, Casper KB, Philpot BD, Chin LS, McCarthy KD (2007) Conditional knock-out of Kir4.1 leads to glial membrane depolarization, inhibition of potassium and glutamate uptake, and enhanced short-term synaptic potentiation. J Neurosci 27:11354-11365.

26. Päsler D, Gabriel S, Heinemann U (2007) Two-pore-domain potassium channels contribute to neuronal potassium release and glial potassium buffering in the rat hippocampus. Brain Res 1173:14-26.

27. Benesova J, Rusnakova V, Honsa P, Pivonkova H, Dzamba D, Kubista M, Anderova M (2012) Distinct expression/function of potassium and chloride channels contributes to the diverse volume regulation in cortical astrocytes of GFAP/EGFP mice. PLoS One 7:e29725.

28. Ringel F, Plesnila N (2008) Expression and functional role of potassium-chloride cotransporters (KCC) in astrocytes and C6 glioma cells. Neurosci Lett 442:219-223.

29. Ryoo K, Park JY (2016) Two-pore domain potassium channels in astrocytes. Exp Neurobiol 25:222-232.

30. Hwang EM, Kim E, Yarishkin O, Woo DH, Han KS, Park N, Bae Y, Woo J, Kim D, Park M, Lee CJ, Park JY (2014) A disulphide-linked heterodimer of TWIK-1 and TREK-1 mediates passive conductance in astrocytes. Nat Commun 5:3227.

31. Simard M, Nedergaard M (2004) The neurobiology of glia in the context of water and ion homeostasis. Neuroscience 129:877-896.

32. Okada Y, Sato K, Numata T (2009) Pathophysiology and 
puzzles of the volume-sensitive outwardly rectifying anion channel. J Physiol 587:2141-2149.

33. Abdullaev IF, Rudkouskaya A, Schools GP, Kimelberg HK, Mongin AA (2006) Pharmacological comparison of swellingactivated excitatory amino acid release and Cl- currents in cultured rat astrocytes. J Physiol 572:677-689.

34. Lambert IH, Hoffmann EK, Pedersen SF (2008) Cell volume regulation: physiology and pathophysiology. Acta Physiol (Oxf) 194:255-282.

35. Nagelhus EA, Ottersen OP (2013) Physiological roles of aquaporin-4 in brain. Physiol Rev 93:1543-1562.

36. Szu JI, Binder DK (2016) The role of astrocytic aquaporin-4 in synaptic plasticity and learning and memory. Front Integr Nuerosci 10:8. 